\title{
New-Onset Diabetes in Obese Adolescents - Type 1 or Type 2 Diabetes? Comparative Cases Report
}

\author{
Anna M. Gertig*, Elżbieta Niechciał, Bogda Skowrońska and Piotr Fichna
}

Department of Pediatric Diabetes and Obesity, Poznan University of Medical Sciences, Poland

\begin{abstract}
The increasingly obesogenic environment exerts a ponderous impact on the clinical presentation and the course of diabetes. Obesity is strongly linked to T2DM development, yet, the latest observation has shown that more cases of T1DM are diagnosed in youth who had been obese before the onset of the disease. What is more, the presence of autoimmunity is noticed in patients phenotypically classified as T2DM. The overlap of the clinical phenotypes of diabetes has become a new challenge for physicians who formulate a differential diagnosis. There is a question to consider how such patients should be classified. Not to discount the importance of identifying diabetes in an obese child, it is the therapeutic approach to such a complex patient that a physician should mainly focus on. Cases presented herein address the role that childhood obesity plays in making a differential diagnosis of diabetes and even more in choosing the adequate therapy.
\end{abstract}

Keywords: Obesity; T1DM; T2DM; Double diabetes; LADY; Diagnosis; Diabetes autoantibodies; treatment

Abbreviations: T1DM: Type 1 Diabetes; T2DM: Type 2 Diabetes; LADY: Latent Autoimmune Diabetes in Youth; LADA: Latent Autoimmune Diabetes in Adults; CS: Caesarean Section; SVD: Spontaneous Vaginal Delivery; HT: Hypertension; BMI: Body Mass index; A1c: Glycated Hemoglobin; HDL: High-Density Lipoprotein; LDL: Low-Density Lipoprotein; IAA: Anti-Insulin Antibodies; GAD: Glutamic Acid Decarboxylase Antibodies; IA2: Tyrosine Phosphatase-like Protein Antibodies; aTPO: Anti- Thyroperoxidase Antibodies; aTG: Anti-Thyroglobulin Antibodies; TSH: ThyroidStimulating Hormone; FT4: Free Thyroxine; USG: Ultrasound; RBG: Random Blood Glucose; FPG: Fasting Plasma Glucose; GP: General Practitioner; TDI: Total Daily Insulin; OID: Once a Day; TID: Twice a Day; APS III: Autoimmune Polyendocrine Syndrome III; ISPAD: The International Society for Pediatric and Adolescent Diabetes; CDC: Centers for Disease Control and Prevention; DASP: Diabetes Antibody Standardization Program; RIA: Radioimmunoassay

\section{Introduction}

Having been facing the progressive increase in the prevalence of childhood obesity in both the industrialized and developing countries, an overlap of the clinical phenotypes of diabetes is frequently witnessed, making it increasingly challenging to differentiate among the types of the disease. Childhood obesity has become one of the most serious public health challenges of the $21^{\text {st }}$ century. Currently $10 \%$ of children worldwide are either overweight or obese, with the increasing weight gain affecting over 42 million of those under the age of 5 years [1,2]. Although in Europe the prevalence of childhood obesity still tends to be lower than in the US, the gap between these two continents is noticeably narrowing [3,4]. It is especially visible in Poland and England, where a recent report conducted by International Obesity Task Force (March 2005) has shown the steepest increase in the prevalence of obesity among children aged 5-11 years [5].

The current epidemiological data also indicate a marked increase in the prevalence of T1DM in childhood population worldwide. The number of diabetic children aged 0-14 years is estimated to be 490.1 thousands. The rise of incidence of T1DM has been witnessed over the past decades, with younger patients accounting for the majority of newly diagnosed cases. An annual increase of the incidence equals 3\% [6]. Moreover, it has recently become apparent that more cases of T1DM are diagnosed in children and adolescents who had been overweight or even obese before the onset of the disease $[7,8]$. Furthermore, the obesogenic environment has been associated with the increasing prevalence of T2DM in the younger age groups, which until recently was rarely diagnosed in children [9-11]. Although obesity is strongly linked to T2DM development, latest data have shown that it also plays a significant role and exerts its effects on other types of diabetes.

Moreover, obesity has changed the clinical presentation and the course of diabetes. For these reasons, both phenotypic characteristics and clinical presentation of different types of the disease have dramatically altered. Both the changing phenotype of T1DM in the youth and the increasing prevalence of T2DM in childhood population have become a new challenge for physicians who make a differential diagnosis of diabetes and especially for its further therapy.

The authors hereof present a comparison of two obese adolescents who presented a different clinical manifestation at the onset of diabetes mellitus.

\section{Cases Presentation}

\section{Case 1}

A 14-yr-old boy presented to the Department of Pediatric Diabetes with a 1-month history of polydypsia and polyuria. In the three months leading up to the presentation he had undergone an unintentional weight loss of $\sim 8 \mathrm{~kg}$.

${ }^{*}$ Corresponding author: Anna M. Gertig, Department of Pediatric Diabetes and Obesity, Children's Hospital, Szpitalna Street 27/33, 60-572 Poznan, Poland, Tel: +48 618491 420; Fax: +48 618491 492; E-mail: anna.gertig@interia.pl

Received July 07, 2013; Accepted August 21, 2013; Published August 27, 2013

Citation: Gertig AM, Niechciał E, Skowrońska B, Fichna P (2013) New-Onset Diabetes in Obese Adolescents - Type 1 or Type 2 Diabetes? Comparative Cases Report. J Diabetes Metab S11: 006. doi:10.4172/2155-6156.S11-006

Copyright: ( 2013 Gertig AM, et al. This is an open-access article distributed under the terms of the Creative Commons Attribution License, which permits unrestricted use, distribution, and reproduction in any medium, provided the original author and source are credited. 
The patient was born on term by CS (due to cross-birth) following an uncomplicated pregnancy. His birth weight was $3200 \mathrm{~g}$, Apgar scores 10. His prenatal history was unremarkable. He has been obese since the age of $6 \mathrm{yr}$ but was otherwise healthy and receiving no medication. Family history was positive for T2DM (maternal grandfather and paternal grand-mother), HT (mother) and obesity (paternal grandparents).

On admission his body weight was $113 \mathrm{~kg}$ (>97 percentile) and height was $173 \mathrm{~cm}$ (50-75 percentile), yielding a BMI of $37.1 \mathrm{~kg} / \mathrm{m}^{2}$, well above the $97^{\text {th }}$ percentile for his age and gender in accordance with Polish 2010 growth references for school-aged children and adolescents by Kułaga et al. [12]. The obesity was generalized, and there was no acanthosis nigricans. Pubertal stage was Tanner $3 / 4$.

Laboratory work-up: Laboratory work-up was remarkable for hyperglycemia (347 mg/dl; $19.2 \mathrm{mmol} / \mathrm{l})$, elevated A1c (13.1\%; 120 $\mathrm{mmol} / \mathrm{mol})$, and the urinalysis revealed both glucosuria $(>1,000 \mathrm{mg} /$ $\mathrm{dl})$ and ketonuria (>80 mg/dl). Fasting lipid profile showed decreased $\mathrm{HDL}$ and increased LDL levels $(21 \mathrm{mg} / \mathrm{dl}$ and $145 \mathrm{mg} / \mathrm{dl}$, respectively). Liver and kidney tests were both normal. Before the onset of medical therapy fasting insulin and c-peptide levels were $5.1 \mathrm{uU} / \mathrm{ml}$ and 1.21 $\mathrm{pmol} / \mathrm{ml}$, respectively. Autoantibodies IAA, GAD and IA2 were weakly positive (Table 1).

Treatment and follow-up: The tentative diagnosis was T1DM, and treatment with insulin $(\sim 0.3 \mathrm{U} / \mathrm{kg} / \mathrm{day})$ as well as diet and exercise were initiated. Within one month, the patient's BMI dropped to $35.5 \mathrm{~kg} /$ $\mathrm{m}^{2}$ and he achieved glycemic goals requiring decreased insulin doses ( $\sim 0.1 \mathrm{U} / \mathrm{kg} /$ day). During the course of the next 4 months, patient's BMI decreased to $33.9 \mathrm{~kg} / \mathrm{m}^{2}$ after the first 6 weeks and further down to $30.4 \mathrm{~kg} / \mathrm{m}^{2}$ after the next 12 weeks. During that period insulin was discontinued from his regimen. He maintained good metabolic control (A1c 5.6\%; $38 \mathrm{mmol} / \mathrm{mol}$ ) following recommendations regarding diet and increased physical activity in accordance with ISPAD guidelines [13] (Table 2).

\section{Case 2}

A 17-yr-old girl was referred to Diabetes Outpatients Clinic by GP due to elevated fasting plasma glucose level $(108-110 \mathrm{mg} / \mathrm{dl} ; 6.0-6.1$ $\mathrm{mmol} / \mathrm{l}$ ) in generally good condition.

The patient was born on term by SVD following an uncomplicated

\begin{tabular}{|l|l|l|l|}
\hline PARAMETER & PATIENT 1 & PATIENT 2 & NORMAL RANGE \\
\hline INSULIN $[\mu / \mathrm{ml}]$ & 5.1 & 6.9 & $5.0-15.0$ \\
\hline $\begin{array}{l}\text { PEPTIDE C [pmol/ } \\
\mathrm{ml}]\end{array}$ & 1.21 & 0.62 & $0.59-1.56$ \\
\hline IAA [\%] * & 5.7 & 5.5 & $<5.5$ \\
\hline GAD [U/ml] * & 4.5 & 19.3 & $<1$ \\
\hline IA2 [U/ml] * & 4.1 & 45.4 & $<1$ \\
\hline TSH $[\mu / \mathrm{U} / \mathrm{ml}]$ & 1.694 & 7.898 & $0.470-4.640$ \\
\hline FT4 $[\mathrm{ng} / \mathrm{dl}]$ & 1.03 & 0.98 & $0.71-1.85$ \\
\hline aTPO [U/ml] & 0 & 709 & $<60$ \\
\hline aTG $[\mathrm{U} / \mathrm{ml}]$ & 43 & 62 & $<60$ \\
\hline
\end{tabular}

Three of recommended by IDF/ISPAD guidelines autoantibodies were measured in our patients

Standardized assays were used to evaluate IAA, GAD and IA2 autoantibodies (RIA, DIAsource Immunoassays S.A. for IAA and RIA, EUROIMMUN Medizinische Labordiagnostika AG for GAD and IA2 evaluation). Both GAD and IA2 assays were evaluated by DASP (2005) and showed both high sensitivity and specificity (a sensitivity of $84 \%$ and $70 \%$, and specificity of $95 \%$ and $100 \%$, respectively) [49-51]

Table 1: Patients' laboratory data summary. pregnancy. Her birth weight was 2950 grams, Apgar scores 10. Her prenatal history was unremarkable. She has been overweight since early childhood, with rapid progression to obesity during pubertal period. The girl did not present symptoms of T1DM such as polyuria, polydipsia and weight loss. She did not have any coexisting disorders. Family history was negative for diabetes and autoimmune diseases and positive for obesity and HT (father).

The physical examination revealed the weight $95 \mathrm{~kg}(>97$ percentile), height $170 \mathrm{~cm}$ (75-90 percentile), BMI $33.3 \mathrm{~kg} / \mathrm{m}^{2}$ (>97 percentile) [12], acanthosis nigricans on the neck and the axilla. Palpable thyroid gland with normal TSH level. Pubertal stage was Tanner 4/5. Based on clinical examination and laboratory results (impaired FPG) the diagnosis of obesity and prediabetes was made. The observation for type 2 diabetes was started and an adequate life style changes were initiated.

At her next visit 3 months later a visible metabolic improvement was noticed, she lost $10 \mathrm{~kg}$. In her opinion, this achievement was a result of her compliance with a low-caloric diet and increased physical activity. However, glucose levels measured on her glucometer were abnormal (>200 mg/dl; >11.1 mmol/l). No additional signs and symptoms were present. She was referred to the Department of Pediatric Diabetes, presumed to be a new-onset type 2 diabetic patient.

Laboratory work-up: On admission to the hospital her laboratory work-up was remarkable for hyperglycemia $(311 \mathrm{mg} / \mathrm{dl} ; 17.2 \mathrm{mmol} / \mathrm{l})$, elevated A1c $(10.4 \% ; 90 \mathrm{mmol} / \mathrm{mol})$, and the urinalysis revealed both glucosuria $(>1,000 \mathrm{mg} / \mathrm{dl})$ and ketonuria $(40 \mathrm{mg} / \mathrm{dl})$. Before the onset of medical therapy fasting insulin and c-peptide levels were $6.9 \mathrm{uU} /$ $\mathrm{ml}$ and $0.62 \mathrm{pmol} / \mathrm{ml}$, respectively. Autoantibodies IAA, GAD and IA2 were positive. Additional laboratory studies revealed TSH 7.898 uIU/ $\mathrm{ml}$, FT4 $0.98 \mathrm{ng} / \mathrm{dl}$. USG of thyroid gland showed a diffusely enlarged thyroid gland with a heterogeneous echogenicity. She was found to be positive for aTPO and aTG antibodies (Table 1).

Treatment and follow-up: The diagnosis of T1DM was made and a split-mixed insulin regimen $(\sim 0.5 \mathrm{U} / \mathrm{kg} /$ day $)$ as well as fixed carbohydrate reduced-fat meal plan and exercise were initiated. Moreover, Hashimoto's thyroiditis was diagnosed and Thyroxine at 50 $\mu \mathrm{g}$ daily dose was added to her therapeutic regimen.

During the course of the next 4 months, patient's BMI was stable $\left(29.4 \mathrm{~kg} / \mathrm{m}^{2}\right)$ after the first 4 weeks, and increased to $31.1 \mathrm{~kg} / \mathrm{m}^{2}$ after the next 4 weeks. During that period her insulin requirement has been slowly increasing ( $0.6 \mathrm{unit} / \mathrm{kg} / \mathrm{day})$, with average glucose levels of 110 - $180 \mathrm{mg} / \mathrm{dl}(6.1-10.0 \mathrm{mmol} / \mathrm{l})$ and A1c- $6.9 \%$ (52 mmol $/ \mathrm{mol})$. At that point $500 \mathrm{mg}$ metformin TID was added to her treatment. After the next 3 months she reduced BMI to 29.8, decreased insulin doses $(\sim 0.4$ $\mathrm{U} / \mathrm{kg} /$ day) and achieved acceptable metabolic control (A1c $6.3 \%$; 45 $\mathrm{mmol} / \mathrm{mol}$ ) (Table 3).

\section{Discussion}

According to the current nomenclature diabetes is generally divided into 'type 1 diabetes' and 'type 2 diabetes'. To distinguish one type from the other guidelines with useful differentiating features have been proposed [13]. But a question arises whether these clinical discriminators can be really relevant for a clinician who makes this differential diagnosis at present.

As illustrated in the cases described, distinction between T1DM and T2DM becomes blurred. From a clinical stand point, there were only two common features in our patients: obesity and adolescence as an age of the onset of the disease. All the other characteristics were different 
Citation: Gertig AM, Niechciał E, Skowrońska B, Fichna P (2013) New-Onset Diabetes in Obese Adolescents - Type 1 or Type 2 Diabetes? Comparative Cases Report. J Diabetes Metab S11: 006. doi:10.4172/2155-6156.S11-006

and strongly suggested wrong initial diagnosis (Table 4). Based on the initial data, the boy received treatment as type 1 diabetic patient. On the other hand, the girl was presumed to have type 2 prediabetes and adequate treatment was initiated.

In accordance with the guidelines the presence of immune markers of beta cell disease is the most widely used criterion to confirm T1DM. However, the autoantibodies are also detected in general population of schoolchildren with the prevalence of 0.5 to $1.8 \%$ [14,15]. Moreover, they are present in children with diabetes phenotypically classified as T2DM with different studies reporting the frequencies from 30 to $75 \%$ [16-18]. However, recent data from TODAY study showed that only as many as $10 \%$ of adolescents with the typical features of T2DM upon further examination turned out to have signs of $\beta$-cell autoimmunity [19]. The question is whether it is just a presence of autoantibodies or maybe it is their titer that should be taken under consideration while differentiating the types of diabetes. All three measured autoantibodies, evaluated by standardized assays, were positive in our patients. Yet, the levels of GAD and IA2 greatly differed in both cases (Table 1). Although detection of islet autoantibodies is increasingly available to clinicians, an unambiguous interpretation of their different titers remains to be elucidated.

Another question that arises is how one should classify an obese diabetic patient with the coexistence of both insulin resistance features and the presence of autoimmunity? Do we need any innovation in the diabetic nomenclature? Terms such as "double diabetes", " hybrid", "mixed" or "type 1.5 diabetes" have recently been used to describe overweight or obese children with the combination of markers typical for both type 2 and type 1 diabetes [20-22]. Concurrently, term LADY has been introduced, describing young patients with islet antibodies and slowly progressive $\beta$-cell failure [23-28]. It is worth further research whether 1.5 diabetes is tantamount to LADY in obese adolescent and whether they have a common pathophysiological origin.

Based on present knowledge and follow-up period, we believe that our male patient presents a case that could be described as T2DM with symptoms including ketonuria at the onset of the disease, slightly positive autoantibodies and preserved insulin secretion. T2DM diagnosis would be consistent with his achievement of good metabolic control by having been compliant to diet and physical

\begin{tabular}{|l|l|l|l|l|}
\hline DATE & JAN 2013 (admision to the hospital) & FEB 2013 - 1st follow-up & MAR 2013 - 2nd follow-up JUN 2013 - 3rd follow-up \\
\hline BODY WEIGHT [kg] & 113 & 107 & 102.7 & 174 \\
\hline HEIGHT $[\mathrm{cm}]$ & 173 & 173.5 & 175 \\
\hline BMI $\left[\mathrm{kg} / \mathrm{m}^{2}\right]$ & 37.1 & 35.5 & 33.9 \\
\hline GLYCEMIA [mg/dl] & $347-$ on admission 80-220 - after initial of treatment & $97-140$ & $70-120$ \\
\hline A1c [\%] & 13.1 & & 6.5 \\
\hline TREATMENT & Insulin 0.3U/kg/d Diet and exercise & Insulin 0.1U/kg/d Diet and exercise Diet and exercise & $70-120$ \\
\hline
\end{tabular}

Table 2: Patient's 1 therapeutic management.

\begin{tabular}{|c|c|c|c|c|c|c|}
\hline DATE & $\begin{array}{l}\text { SEP } 2012 \text { - 1st visit in } \\
\text { Outpatients Clinic }\end{array}$ & $\begin{array}{l}\text { DEC } 2012 \text { - 2nd visit } \\
\text { in Outpatients Clinic }\end{array}$ & $\begin{array}{l}\text { DEC } 2012 \text { (admission } \\
\text { to the hospital) }\end{array}$ & $\begin{array}{l}\text { JAN } 2013 \text { - 1st } \\
\text { follow-up }\end{array}$ & $\begin{array}{l}\text { FEB } 2013 \text { - 2nd follow } \\
\text { up }\end{array}$ & $\begin{array}{l}\text { MAY } 2013 \text { - 3rd follow- } \\
\text { up }\end{array}$ \\
\hline BODY WEIGHT [kg] & 95 & 85.5 & 85.5 & 85 & 90 & 86 \\
\hline HEIGHT [cm] & 170 & 170 & 170 & 170 & 170 & 170 \\
\hline BMI $\left[\mathrm{kg} / \mathrm{m}^{2}\right]$ & 33,3 & 29.7 & 29.7 & 29.4 & 31.1 & 29.8 \\
\hline GLYCEMIA [mg/dl] & $108-110$ & $200-300$ & 311 & $120-160$ & $110-180$ & $70-150$ \\
\hline $\mathrm{A} 1 \mathrm{c}[\%]$ & & & 10.4 & & 6.9 & 6.3 \\
\hline TREATMENT & Diet and exercise & Hospital Referral & $\begin{array}{l}\text { Insulin: } \sim 0.5 \mathrm{U} / \mathrm{kg} / \mathrm{d} \\
\text { Thyroxine } 50 \mu \mathrm{g} \text { OID } \\
\text { Diet and exercise }\end{array}$ & $\begin{array}{l}\text { Insulin: } \sim 0.5 \text { U/ } \\
\text { kg/d Thyroxine } 50 \\
\mu g \text { OID Diet and } \\
\text { exercise }\end{array}$ & $\begin{array}{l}\text { Insulin: } \sim 0.6 \mathrm{U} / \mathrm{kg} / \mathrm{d} \\
\text { Metformin } 500 \mathrm{mg} \text { TID } \\
\text { Thyroxine } 50 \mu \mathrm{g} \text { OID } \\
\text { Diet and exercise }\end{array}$ & $\begin{array}{l}\text { Insulin: } \sim 0.4 \mathrm{U} / \mathrm{kg} / \mathrm{d} \\
\text { Metformin } 500 \mathrm{mg} \text { TID } \\
\text { Thyroxine } 50 \mu \mathrm{g} \text { OID } \\
\text { Diet and exercise }\end{array}$ \\
\hline
\end{tabular}

Table 3: Patient's 2 therapeutic management.

\begin{tabular}{|c|c|c|}
\hline Characteristic & Patient 1 & Patient 2 \\
\hline Age of onset & Pubertal period & After puberty \\
\hline Clinical presentation & Rapid & Slow \\
\hline Autoimmunity & Weakly positive & Positive \\
\hline Ketonuria & ++ & + \\
\hline Glycemia & High & High \\
\hline Obesity & Yes & Yes \\
\hline Acanthosis nigricans & No & Yes \\
\hline Additional autoimmune disease & No & Yes \\
\hline Diagnosis of diabetes on routine physical examination & No & Yes \\
\hline T2D in family history & Yes & No \\
\hline HTN in family history & Yes & Yes \\
\hline Obesity in family history & No & Yes \\
\hline Autoimmune disease in family history & No & No \\
\hline
\end{tabular}

(Highlighted features characteristic for T2DM)

This table shows how blurred the initial diagnosis of DM in such patients can be. Despite presence of obesity, rapidly developing symptoms accompanied by hyperglycemia and elevated A1C seen in our male patient suggested T1DM diagnosis. On the other hand, the girl presented the typical clinical phenotype of T2DM with features of insulin resistance (obesity, acanthosis nigricans) and slow clinical presentation,but also with high titers of islet autoantibodies 
activity recommendations. Yet, at this point of the course of the disease we cannot rule out a future development of an insulin-dependency. If such a situation occurs, he will be diagnosed as LADY characterized by the slow progression of $\beta$-cell dysfunction [29]. Such a case report was presented by Zachariah et al., who demonstrated that autoimmune diabetes can be slowly progressive even in younger patients with insulin independency period lasting for more than two years [30]. Conversely, our female patient rather seems to have T1DM, with high titers of autoantibodies and lower endogenous insulin production. Concomitantly, she was diagnosed with autoimmune thyroiditis, which coexists commonly with T1DM as a part of APS III [31]. However, she should not be classified as "classic" T1DM due to presence of obesity previous to diabetes diagnosis. T1DM in an obese child or adolescent might be called "double diabetes" [32]. According to P. Pozzilli a subject may be defined as affected by "double diabetes" in two clinical situations: when a child with T2DM has autoantibodies to beta cells or when a child with T1DM is overweight/obese, as seen in the case of our patient [33]. Moreover, our female patient exemplifies how beneficial adding metformin to therapeutic regimen may become in such cases ("double treatment" for "double diabetes")

A meta-analysis of 9 studies (total 2658 patients) revealed an association between childhood obesity, or higher BMI, and an increased risk of subsequent type 1 diabetes showing that obesity does not exclude development of autoimmunization process and is not a protective factor against T1DM [34]. What is more, up to $21 \%$ children with a new onset T1DM were overweight or obese in the US population based study conducted by CDC [35]. The suggestion that T1DM and T2DM have a common pathophysiological origin was firstly put forward by Prof. Wilkin TJ in the 'Accelerator Hypothesis', describing weight gain as the missing link between type 1 and type 2 diabetes [36]. The hypothesis emphasizes the role of the body mass place in the development of both type 1 and type 2 diabetes, indicating control thereof as the potential method not only to prevent T2DM, but also to delay T1DM manifestation [37].

The ability to measure insulin resistance consistently across the phenotypic spectrum of diabetes is therefore important as it may contribute to a more accurate characterization of diabetes type. According to SEARCH study, an approach using diabetes autoantibodies and a newly developed algorithm to asses insulin sensitivity based on routine clinical measures (waist circumference, triacylglycerol and A1c) classifies $>90 \%$ of youths with new-onset diabetes into one of the traditional categories. At the same time, it identifies a group of youths who would benefit from further testing to clarify the etiology of diabetes $[38,39]$.

Whereas detailed understanding of the pathogenesis of the types and subtypes of diabetes remains to be elucidated, it is apparent that there is a genetic predisposition on which environmental triggers are superimposed. HLA-typing may lead not only to better comprehension of the pathological background of emerging subtypes of diabetes, but also to avoid misclassification of diabetic patients and to evaluate the risk of the disease in the family members [40]. Although advances in genotyping technology have been witnessed lately, genetic testing for T1DM and T2DM still remains of little value in clinical practice, mainly in pediatric population $[41,42]$.

To conclude, the dilemma of categorizing the type of diabetes in children and adolescents was thoroughly presented. However, not to discount the importance of classifying diabetes in an obese child, it is the therapeutic approach to such a complex patient that a physician should mainly focus on. Would it be helpful in proposing a better treatment for a patient once we sort out what subtype of diabetes he or she has? It is worth mentioning that since the course of T2DM relies on the presence of islet autoantibodies, the necessity of marking them seems to be equally crucial in further therapeutic decisions [43]. Nevertheless, it seems reasonable to treat a patient based on his or her actual needs: insulin deficiency will always require treatment with insulin, while insulin resistance gives us a choice of a few therapeutic approaches. Yet, therapeutic options for type 2 diabetic children and adolescents are limited [44]. While we follow guidelines treating patients with classic types of diabetes, it is still unclear how to approach non-classic picture of the disease, particularly in the long-term treatment. It is worth mentioning that diabetic patients with preserved beta cells function and concomitant high levels of autoantibodies may benefit from early insulin treatment [45]. On the other hand, there is some evidence of a significant effect of metformin used in type 1 diabetic patients, especially those with poor control of the disease and coexisting obesity [46-48]. However, regardless of the type of diabetes we have to deal with and the therapeutic approach we choose, still the main goal is to prevent chronic complications by achieving a good metabolic control of the disease [49-51].

\section{Conclusions}

- In the face of increasing prevalence of obesity worldwide, the diagnosis of diabetes has become a new challenge for physicians.

- At the onset of diabetes it seems important to put an impact on an adequate treatment, leaving the differential diagnosis to the subtypes of the disease to the follow-up period.

- Based on present knowledge, pathophysiology of new subtypes of diabetes is still unclear, making it often impossible to classify the patient properly.

- Recently, since new phenotypes and courses of diabetes have been observed, common standpoint in the classification of diabetes might be proposed.

\section{References}

1. Shah A (2010) Obesity. Global issues.

2. Bessesen DH (2008) Update on obesity. J Clin Endocrinol Metab 93: 20272034.

3. Anderson SE, Whitaker RC (2009) Prevalence of obesity among US preschoo children in different racial and ethnic groups. Arch Pediatr Adolesc Med 163: 344-348.

4. Lobstein T, Frelut ML (2003) Prevalence of overweight among children in Europe. Obes Rev 4: 195-200.

5. (2005) International Obesity Task Force EU Platform Briefing Paper prepared in collaboration with the European Association for the Study of Obesity.

6. (2011) International Diabetes Federation.

7. Hyppönen E, Virtanen SM, Kenward MG, Knip M, Akerblom HK, et al. (2000) Obesity, increased linear growth, and risk of type 1 diabetes in children. Diabetes Care 23: 1755-1760.

8. Libman IM, Pietropaolo M, Arslanian SA, LaPorte RE, Becker DJ (2003) Changing prevalence of overweight children and adolescents at onset of insulin-treated diabetes. Diabetes Care 26: 2871-2875

9. Dabelea D, Hanson RL, Bennett PH, Roumain J, Knowler WC, et al. (1998) Increasing prevalence of Type II diabetes in American Indian children Diabetologia 41: 904-910.

10. Kaufman FR, Shaw J (2007) Type 2 diabetes in youth: rates, antecedents, treatment, problems and prevention. Pediatr Diabetes 8: 4-6.

11. Pinhas-Hamiel O, Dolan LM, Daniels SR, Standiford D, Khoury PR, et al. 
(1996) Increased incidence of non-insulin-dependent diabetes mellitus among adolescents. J Pediatr 128: 608-615.

12. Kulaga Z, Litwin M, Tkaczyk M, Palczewska I, Zajaczkowska M, et al. (2011) Polish 2010 growth references for school-aged children and adolescents. Eur J Pediatr 170: 599-609.

13. (2011) Global IDF/ISPAD Guideline for Diabetes in Childhood and Adolescence.

14. Kondrashova A, Viskari H, Kulmala P, Romanov A, llonen J, et al. (2007) Signs of beta-cell autoimmunity in nondiabetic schoolchildren: a comparison between Russian Karelia with a low incidence of type 1 diabetes and Finland with a high incidence rate. Diabetes Care 30: 95-100.

15. Cambuli VM, Incani M, Cossu E, Congiu T, Scano F, et al. (2010) Prevalence of type 1 diabetes autoantibodies (GADA, IA2, and IAA) in overweight and obese children. Diabetes Care 33: 820-822.

16. Hathout EH, Thomas W, El-Shahawy M, Nahab F, Mace JW (2001) Diabetic autoimmune markers in children and adolescents with type 2 diabetes. Pediatrics 107: E102.

17. Umpaichitra V, Banerji MA, Castells S (2002) Autoantibodies in children with type 2 diabetes mellitus. J Pediatr Endocrinol Metab 15: 525-530.

18. Brooks-Worrell BM, Greenbaum CJ, Palmer JP, Pihoker C (2004) Autoimmunity to islet proteins in children diagnosed with new-onset diabetes. J Clin Endocrinol Metab 89: 2222-2227.

19. Klingensmith GJ, Pyle L, Arslanian S, Copeland KC, Cuttler L, et al. (2010) The presence of GAD and IA-2 antibodies in youth with a type 2 diabetes phenotype: results from the TODAY study. Diabetes Care 33: 1970-1975.

20. Pozzilli P, Guglielmi C, Pronina E, Petraikina E (2007) Double or hybrid diabetes associated with an increase in type 1 and type 2 diabetes in children and youths. Pediatr Diabetes 8: 88-95.

21. Pozzilli P, Buzzetti $R$ (2007) A new expression of diabetes: double diabetes. Trends Endocrinol Metab 18: 52-57.

22. Purushothaman R, Ramchandani N, Kazachkova I, Ten S (2007) Prevalence and clinical features of type 1.5 diabetes mellitus in children. J Pediatr Endocrinol Metab 20: 981-987.

23. Ohtsu S, Takubo N, Kazahari M, Nomoto K, Yokota F, et al. (2005) Slowly progressing form of type 1 diabetes mellitus in children: genetic analysis compared with other forms of diabetes mellitus in Japanese children. Pediatr Diabetes 6: 221-229.

24. Chiu HK, Tsai EC, Juneja R, Stoever J, Brooks-Worrell B, et al. (2007) Equivalent insulin resistance in latent autoimmune diabetes in adults (LADA) and type 2 diabetic patients. Diabetes Res Clin Pract 77: 237-244.

25. Desai M, Cull CA, Horton VA, Christie MR, Bonifacio E, et al. (2007) GAD autoantibodies and epitope reactivities persist after diagnosis in latent autoimmune diabetes in adults but do not predict disease progression: UKPDS 77. Diabetologia 50: 2052-2060.

26. Reinehr T, Schober E, Wiegand S, Thon A, Holl R, et al. (2006) Betacell autoantibodies in children with type 2 diabetes mellitus: subgroup or misclassification? Arch Dis Child 91: 473-477.

27. Rosário PW, Reis JS, Fagundes TA, Calsolari MR, Amim R, et al. (2007) Laten autoimmune diabetes in adults (LADA): usefulness of anti-GAD antibody titers and benefit of early insulinization. Arq Bras Endocrinol Metabol 51: 52-58.

28. van Deutekom AW, Heine RJ, Simsek S (2008) The islet autoantibody titres: their clinical relevance in latent autoimmune diabetes in adults (LADA) and the classification of diabetes mellitus. Diabet Med 25: 117-125.

29. Cernea S, Buzzetti R, Pozzilli P (2009) Beta-cell protection and therapy for latent autoimmune diabetes in adults. Diabetes Care 32: S246-252.

30. Zachariah S, Sharfi MO, Nussey SS, Bano G (2008) Latent autoimmune diabetes in the young. Clin Med 8: 552-553.

31. Ben-Skowronek I, Michalczyk A, Piekarski R, Wysocka-Lukasik B, Banecka B
(2013) Type III Polyglandular Autoimmune Syndromes in children with type 1 diabetes mellitus. Ann Agric Environ Med 20: 140-146.

32. Cizza G, Brown RJ, Rother KI (2012) Rising incidence and challenges of childhood diabetes. A mini review. J Endocrinol Invest 35: 541-546.

33. Pozzilli P, Guglielmi C, Caprio S, Buzzetti R (2011) Obesity, autoimmunity, and double diabetes in youth. Diabetes Care 34: S166-170.

34. Verbeeten KC, Elks CE, Daneman D, Ong KK (2011) Association between childhood obesity and subsequent Type 1 diabetes: a systematic review and meta-analysis. Diabet Med 28: 10-18.

35. Kaminski BM, Klingensmith GJ, Beck RW, Tamborlane WV, Lee J, et al. (2013) Body mass index at the time of diagnosis of autoimmune type 1 diabetes in children. J Pediatr 162: 736-740.

36. Wilkin TJ (2001) The accelerator hypothesis: weight gain as the missing link between Type I and Type II diabetes. Diabetologia 44: 914-922.

37. Wilkin TJ (2012) The convergence of type 1 and type 2 diabetes in childhood the accelerator hypothesis. Pediatr Diabetes 13: 334-339.

38. Dabelea D, D'Agostino RB Jr, Mason CC, West N, Hamman RF, et al. (2011) Development, validation and use of an insulin sensitivity score in youths with diabetes: the SEARCH for Diabetes in Youth study. Diabetologia 54: 78-86.

39. Dabelea D, Pihoker C, Talton JW, D’Agostino RB Jr, Fujimoto W, et al. (2011) Etiological approach to characterization of diabetes type: the SEARCH fo Diabetes in Youth Study. Diabetes Care 34: 1628-1633.

40. Awa WL, Boehm BO, Rosinger S, Achenbach P, Ziegler AG, et al. (2013) HLA-typing, clinical, and immunological characterization of youth with type 2 diabetes mellitus phenotype from the German/Austrian DPV database. Pediatr Diabetes

41. Gill-Carey O, Hattersley AT (2007) Genetics and type 2 diabetes in youth Pediatr Diabetes 8 Suppl 9: 42-47.

42. Lyssenko V, Laakso M (2013) Genetic Screening for the Risk of Type 2 Diabetes: Worthless or valuable? Diabetes Care 36 Suppl 2: S120-126.

43. Cefalu WT (2013) "TODAY" reflects on the changing "faces" of type 2 diabetes. Diabetes Care 36: 1732-1734.

44. Tamborlane WV, Klingensmith G (2013) Crisis in care: limited treatment options for type 2 diabetes in adolescents and youth. Diabetes Care 36: 1777-1778.

45. Maruyama T, Tanaka S, Shimada A, Funae O, Kasuga A, et al. (2008) Insulin intervention in slowly progressive insulin-dependent (type 1) diabetes mellitus. $\mathrm{J}$ Clin Endocrinol Metab 93: 2115-2121.

46. Vella S, Buetow L, Royle P, Livingstone S, Colhoun HM, et al. (2010) The use of metformin in type 1 diabetes: a systematic review of efficacy. Diabetologia 53: $809-820$.

47. Särnblad S, Kroon M, Aman J (2003) Metformin as additional therapy in adolescents with poorly controlled type 1 diabetes: randomised placebocontrolled trial with aspects on insulin sensitivity. Eur J Endocrinol 149: 323329.

48. Khan AS, McLoughney CR, Ahmed AB (2006) The effect of metformin on blood glucose control in overweight patients with Type 1 diabetes. Diabet Med 23 1079-1084.

49. Achenbach P, Schlosser M, Williams AJ, Yu L, Mueller PW, et al. (2007) Combined testing of antibody titer and affinity improves insulin autoantibody measurement: Diabetes Antibody Standardization Program. Clin Immunol 122 $85-90$

50. Törn C, Mueller PW, Schlosser M, Bonifacio E, Bingley PJ, et al. (2008) Diabetes Antibody Standardization Program: evaluation of assays for autoantibodies to glutamic acid decarboxylase and islet antigen-2. Diabetologia 51: 846-852.

51. Schlosser M, Mueller PW, Törn C, Bonifacio E, Bingley PJ, et al. (2010) Diabetes Antibody Standardization Program: evaluation of assays for insulin autoantibodies. Diabetologia 53: 2611-2620.
This article was originally published in a special issue, Diabetes, Obesity and their Related Diseases handled by Editor(s). Dr. Massimo Collino, University of Turin, Italy 